Provided for non-commercial research and education use. Not for reproduction, distribution or commercial use.

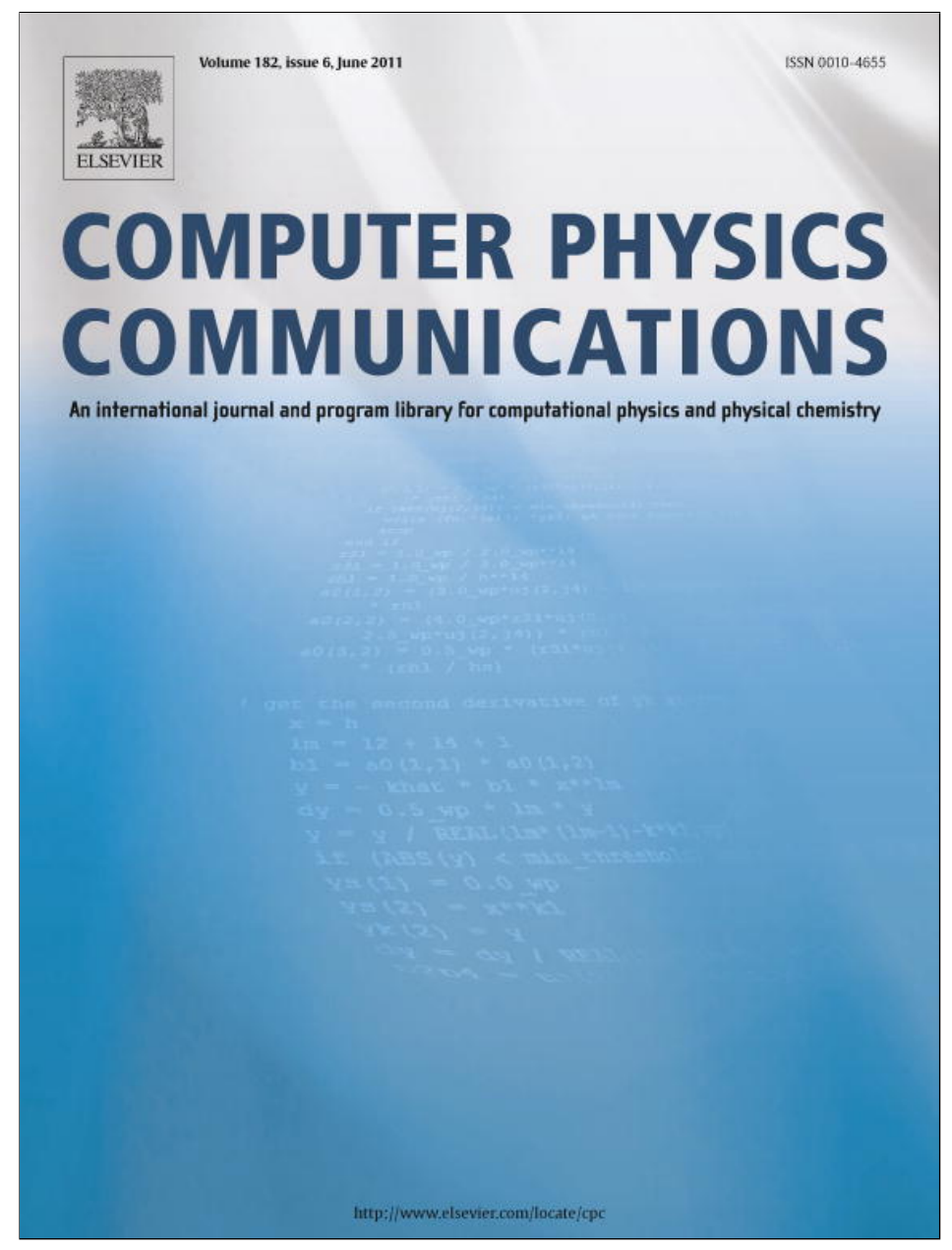

This article appeared in a journal published by Elsevier. The attached copy is furnished to the author for internal non-commercial research and education use, including for instruction at the authors institution and sharing with colleagues.

Other uses, including reproduction and distribution, or selling or licensing copies, or posting to personal, institutional or third party websites are prohibited.

In most cases authors are permitted to post their version of the article (e.g. in Word or Tex form) to their personal website or institutional repository. Authors requiring further information regarding Elsevier's archiving and manuscript policies are encouraged to visit:

http://www.elsevier.com/copyright 


\title{
Handheld modern computer brings new features to portable X-ray fluorescence coating thickness measurement device
}

\author{
Alain Carapelle ${ }^{\mathrm{a}, *}$, Jean-Marc Defise ${ }^{\mathrm{a}}$, David Strivay ${ }^{\mathrm{b}}$, Henri-Pierre Garnir ${ }^{\mathrm{b}}$ \\ a Centre Spatial de Liège, University of Liège, Avenue du Pré-Aily, B-4031 Angleur-Liège, Belgium \\ ${ }^{\mathrm{b}}$ Institut de Physique Nucléaire, Atomique et de Spectroscopie, University of Liège, Sart-Tilman B15, B-4000 Liège, Belgium
}

\section{A R T I C L E I N F O}

\section{Article history:}

Received 6 October 2010

Received in revised form 1 March 2011

Accepted 14 March 2011

Available online 17 March 2011

\section{Keywords:}

Coating

Thickness

X-ray fluorescence

Handheld computer

\begin{abstract}
A B S T R A C T
X-ray fluorescence is routinely used to measure coating thickness on table top setup. The use of a handheld modern computer (PC compatible) gives the possibility to build a portable device with new features. The computer is used to control device's components and to do processor consuming calculation. The user interface is "push button" to allow the utilization by nonspecialized operator.
\end{abstract}

(C) 2011 Elsevier B.V. All rights reserved.

\section{Introduction}

In the frame of its optical coating facilities, the Centre Spatial de Liège (CSL) needs a portable device for the measurement, in the field, of coatings thickness. The device has to be handheld to allow its utilization near different coating facilities. Another requirement is its ease of use; it has to be used by a nonspecialist operator. Therefore the operation of the device has to be as easy as possible. A new algorithm for calibration is used. This algorithm is computational intensive.

The availability of commercial powerful PC handheld computer (Windows operating system) allows the device to be lightweight and portable. As Windows PCs are widely used the device can be operated by almost anyone. The user interface is made as simple as possible: only one start button. Measurement results can be directly saved on another desktop computer via wireless network (WiFi). The data format produced by the device is compatible [1] with specialized X-ray spectrum treatment software WinAxil [2] distributed by Canberra.

\section{Measurement principle}

The principle used by the device is the following: an X-ray tube irradiates the sample and X-ray fluorescence occurs; a detector counts incoming X-ray photons and measures their energies. The X-ray fluorescence spectrum is recorded and analyzed. The in-

\footnotetext{
* Corresponding author.

E-mail address: a.carapelle@ulg.ac.be (A. Carapelle).
}

tensity of one of the fluorescence line of the coating is used to calculate the coating thickness. The use of a computer to control the whole experiment and proceed to data treatment is obvious in modern setup. Section 3 details the device design and computer control and Section 4 details calibration and data treatment algorithm.

\section{Device design}

The computer is used to control the device through two of its element: the multichannel analyzer (MCA) that collects the Xray fluorescence spectrum [3] and the high voltage control of the $\mathrm{X}$-ray tube's high voltage power supply. These two elements can be interfaced via RS-232 serial connections. As modern handheld computers rarely have RS-232 ports (in our case a OQO Model 01 computer), we use a USB hub and two RS-232 to USB converters (RS-232 to Bluetooth converters can also be used).

The MCA is an MCA8000A from Amptek; the X-ray tube is the Model TUB00020-1 with a silver anode from Moxtek, its associated HV supply can provide an adjustable voltage between $10 \mathrm{kV}$ and $35 \mathrm{kV}$, the current is also adjustable up to $0.1 \mathrm{~mA}$. The HV supply controller, the pre-amplifier and the amplifier are developed specifically for this device. Fig. 1 details the principle of the device and computer control and Fig. 2 is a picture of the real device.

During a measurement, the following sequence of operation is done: switch X-ray tube on - wait $1 \mathrm{~s}$ for stabilization - send the measurement time parameter to the MCA - send start command to the MCA - wait during measurement $+1 \mathrm{~s}$ - stop the X-ray tube upload data from the MCA - apply data treatment algorithm - 
display and save results. All these operations are programmed in the computer software.

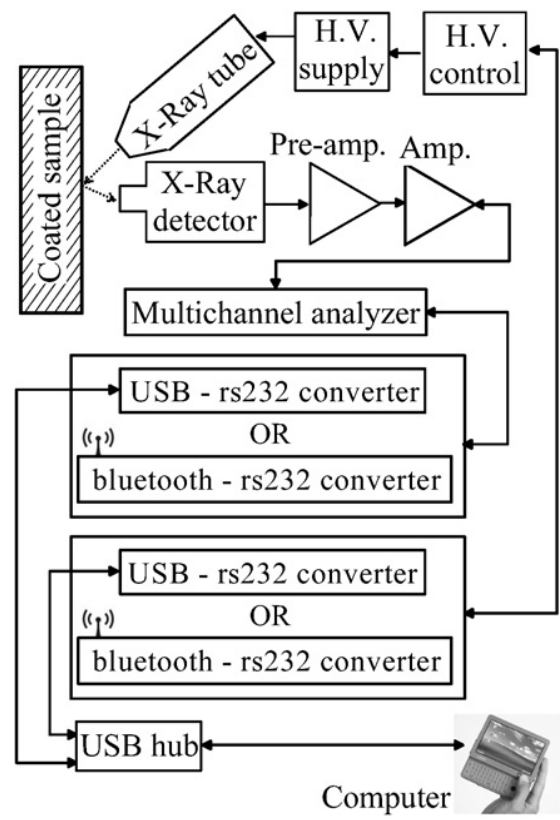

Fig. 1. Device principle and computer control.
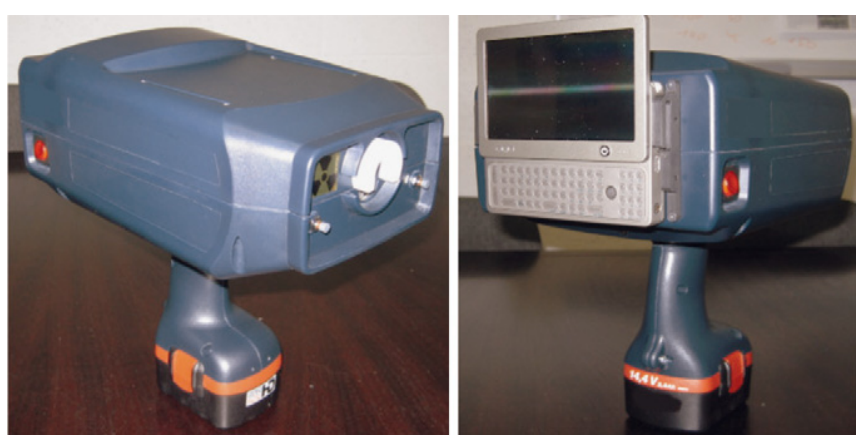

Fig. 2. Picture of the device

\section{Data treatment algorithm}

We calculate the thickness of the coating layer by measuring the yield of one of its fluorescence line. The yield is calculated by measuring the area under the curve in the X-ray fluorescence spectrum in the energy range $E_{1}$ to $E_{2}$ minus the background of trapezoidal shape. Fig. 3 illustrates this calculation.

To obtain an accurate measurement, we must calibrate the device with samples of known thickness; the calibration curve used is a second order polynomial mainly because of self-absorption of the measured layer [4, p. 366] and pile-up and sum-peaks [4, p. 243]. For the calibration curve a fitting of the second order polynomial (parabolic fitting) is done on calibration data. Fig. 4 shows a calibration curve for copper coating on silicon wafer substrate.

One of the drawbacks of this method is the choice of the energy range $E_{1}$ to $E_{2}$ (region of interest or ROI) where the studied fluorescence line is recorded. Even if the fluorescence line is well chosen (high yield, energy near the maximum of the energy response curve of the detector, energy position not too close to a fluorescence line of the substrate of the coating), the fluorescence lines are rather wide (full width at half maximum between 150

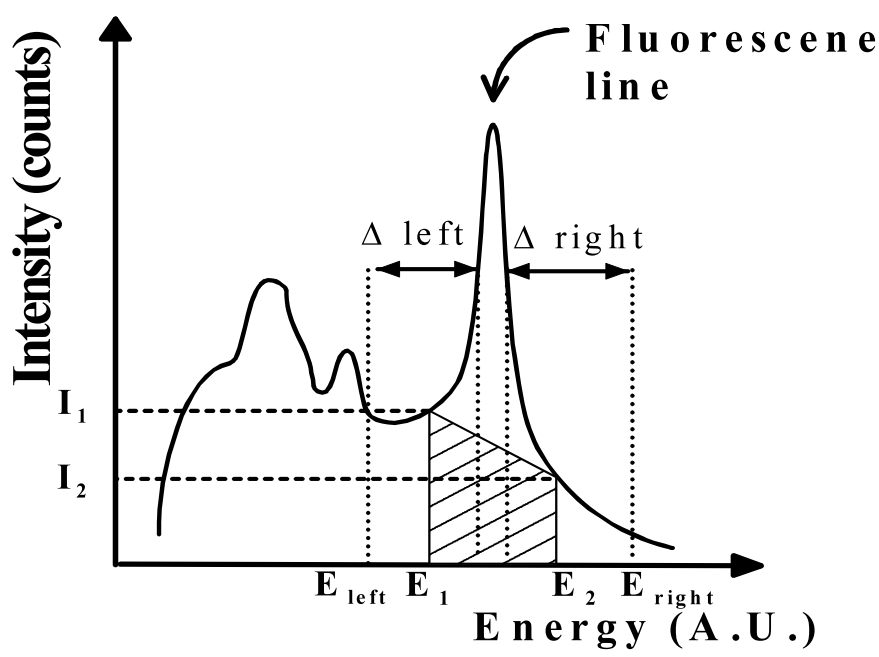

Fig. 3. Yield calculation

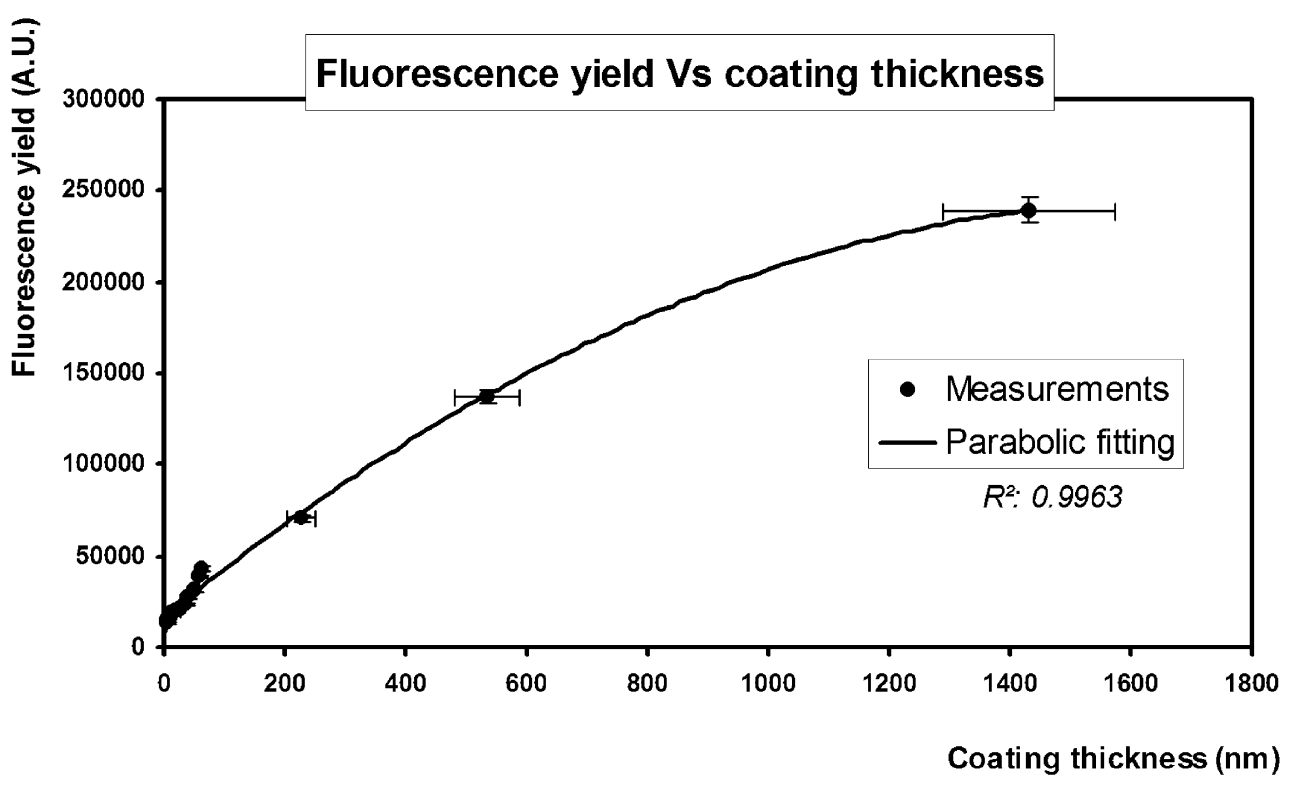

Fig. 4. Copper on silicon calibration curve. 


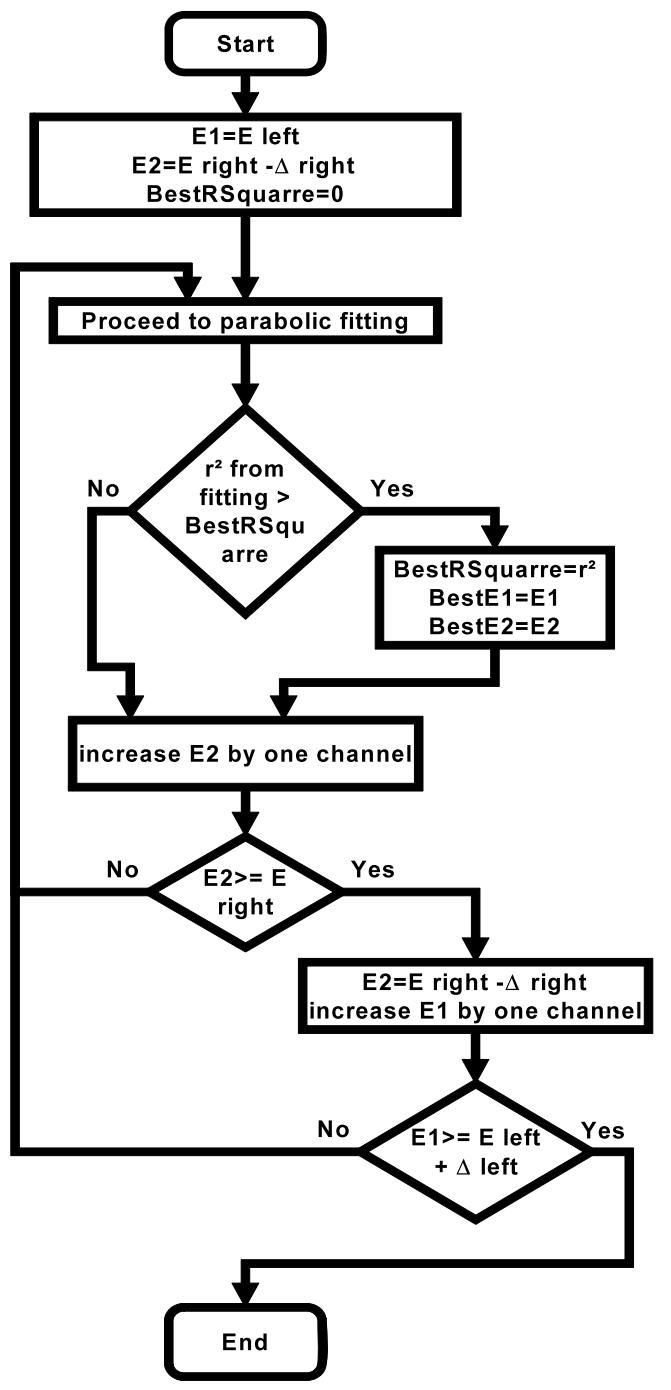

Fig. 5. Algorithm used for the search of best ROI.

and $200 \mathrm{eV}$, mainly because of the detector resolution), and their positions can be affected by experimental conditions (detector resolution degradation due to increase of temperature for long measurement series [5], resolution degradation due to high count rate [4, p. 232], MCA nonlinearity, small $S / N$ ratio). If the ROI (from $E_{1}$ to $E_{2}$ ) is not well chosen, the parabolic fitting in the fluorescence vs coating thickness calibration curve is poor $\left(r^{2}\right.$ decreases from ideal 1 value to indicate a poor fitting). To obtain the best calibration curve and fitting, we have to find the best value for $E_{1}$ and $E_{2}$. Instead of trying manually a few sets of values for $E_{1}$ and $E_{2}$ we can use the power of modern computer to try all the possible values. The algorithm will try all possible values for $E_{1}$ and $E_{2}$ in a given "extended" range from respectively $E_{\text {left }}$ to $E_{\text {left }}+\Delta_{\text {left }}$ and $E_{\text {right }}-\Delta_{\text {right }}$ to $E_{\text {right }}$ and found the best ones, called respectively Best $E_{1}$ and Best $E_{2}$. The best values for $E_{1}$ and $E_{2}$ are the ones that lead to the best parabolic fitting (the one with the higher $r^{2}$ ). Fig. 5 gives the algorithm used for the search of the best ROI (Best $E_{1}$ to Best $E_{2}$ ). Even if this search involves a huge amount of calculation, the computer processes the search of the best ROI in less than $10 \mathrm{~s}$. The program is written in object oriented Pascal language (Delphi); the fitting is done with the Curvefit ActiveX component from MathPack SDL free light edition of Epina Software Labs. After the calibration phase, the fitting equation obtained by the algorithm is used as a calibration curve for the measurements of samples of unknown thicknesses.

\section{Results}

Measurements show that the device can measure accurately the following coatings: $\mathrm{Cu}, \mathrm{Al}, \mathrm{Mg}, \mathrm{Ti}, \mathrm{Cr}, \mathrm{S}, \mathrm{Ru}$ in the range 1 to $2000 \mathrm{~nm}$. For low $Z$ elements $(\mathrm{Mg}, \mathrm{Al}$ and $\mathrm{S})$ measurements must be done under helium flushing to avoid fluorescence absorption by air (mainly argon). When He flushing is used, the pressure and flux of He must be very stable to avoid measurement fluctuations. Due to the X-ray tube intensity instabilities of $\sim 3 \%$ (data provided by manufacturer), the maximum measurements accuracy is, at best, $\sim 3 \%$ (standard deviation). For example, with a series of ten measurements of Ti layer of $\sim 1200 \mathrm{~nm}$ on iron alloy, the calculated statistical deviation obtained is $3.32 \%$. Even for very thin layer of a few atoms, the performances are still good: for a layer of $1.2 \mathrm{~nm}$ of $\mathrm{Zr}\left(8 \mathrm{mg} / \mathrm{m}^{2}\right)$ with He flushing, ten measurement of the same sample gives a standard deviation of $5.78 \%$.

Another application of the device is the detection of lead in space qualified components: ROHS regulation has banned lead in electronic components, but for space application, the absence of lead can cause "whisker" phenomenon [6] and could be a cause of failure. We used our device to test the presence of lead of one connector of the SWAP instrument [7] that is currently on flight [8].

The device can also be used to measure the deposition obtained by laser-induced forward transfer (LIFT) [9]: a series a measurement of gold layers with thickness in the range 0.2 to $1 \mu \mathrm{m}$ deposited on Ni steel has been done.

\section{Conclusions}

As a conclusion, we can say that the advantages obtained by the use of a modern handled computer are:

- Portable and lightweight device.

- Possibility of controlling the setup hardware (MCA and X-ray tube).

- Processing power allow the use of calculation intensive calibration algorithm.

- Ease of use for operator.

- Ease of programming (opposed to microcontroller programming).

- Possibility of use of largely available programming libraries (e.g. fitting procedure, graphical spectrum display, data file saving, etc.).

- Data wireless access (via WiFi)

- Data format compatibility with desktop treatment software (WinAxil).

\section{References}

[1] P. Van Espen, private communication, Antwerp, 2006

[2] B. Vekemans, K. Janssens, L. Vincze, F. Adams, P. Van Espen, X-Ray Spectrom. 23 (1994) 278.

[3] R. Jenkins, X-Ray Fluorescence Spectrometry, 2nd edition, Chemical Analysis, a Series of Monographs on Analytical Chemistry and Its Applications, vol. 152, John Wiley \& Sons, 1999, p. 107.

[4] R.E. Van Grieken, A.A. Markowicsz, Handbook of X-Ray Spectrometry, 2nd edition, Practical Spectroscopy Series, vol. 29, Marcel Dekker, New York, 2002.

[5] P. Lechner, C. Fiorini, R. Hartmann, J. Kemmer, N. Krause, P. Leutenegger, A. Longoni, H. Soltau, D. Stötter, R. Stötter, L. Strüder, U. Weber, Nucl. Instr. Meth. A 458 (2001) 281.

[6] B.D. Dunn, Soldering \& Surface Mount Technol. 20 (4) (2008) 37.

[7] J.-M. Defise, J.-P. Halain, D. Berghmans, F. Denis, E. Mazy, P. Rochus, T. Thibert J.-H. Lecat, B. Nicula, A. De Groof, J.-F. Hochedez, U. Schühle, M.-F. Ravet, F. Delmotte, Proc. SPIE 6689 (2007) 66890S, 12 pp.

[8] J.-P. Halain, D. Berghmans, J.-M. Defise, E. Renotte, T. Thibert, E. Mazy, P. Rochus, B. Nicula, A. De Groof, D. Seaton, U. Schühle, Proc. SPIE 7732 (24) (2010) 77320P, $11 \mathrm{pp}$.

[9] K. Fleury-Frenette, P. Gailly, A. Kupisiewicz, M. Denoël, L. Langer, Characteristics of LIFT deposited gold coatings, in: Proceedings of the European Conference on Nano Films, Liège, 2010. 